\title{
Importância do programa institucional de bolsas de iniciação à docência (PIBID) na formação dos acadêmicos do curso de ciências biológicas
}

\author{
The importance of the institutional program of teaching initiation scholarship \\ (PIBID) in the trainning of the academics of the biological sciences course
}

\section{Importancia del programa institucional de bolsas de iniciación a la docencia (PIBID) en la formación de los académicos del curso de ciencias biológicas}

\author{
Junielson Soares da Silva ${ }^{2}$ \\ Stephanne Marques Araújo Fernandes ${ }^{3}$ \\ Romildo Ribeiro Soares ${ }^{4}$
}

\begin{abstract}
Resumo: A criação de políticas públicas de incentivo à docência, como é o caso do Pibid, tem buscado melhorar a formação inicial de professores e incentivar os licenciandos a seguir a carreira docente. Este trabalho teve como objetivo analisar a importância do Pibid na formação inicial dos licenciandos do curso de Biologia da Universidade Federal do Piauí (UFPI), campus Ministro Petrônio Portela, Teresina. Para isso, foi aplicado um questionário contendo seis perguntas, para 36 bolsistas do Pibid, e a análise dos resultados mostrou que este Programa tem despertado nesses estudantes maior interesse pela docência, além disso, sentem-se mais preparados para atuar no ensino. Conclui-se que o subprojeto Pibid/Biologia da UFPI tem propiciado aos bolsistas, experiências no âmbito da escola de educação básica, despertando nos licenciados, maior interesse pela docência e os tornando mais preparados para as adversidades da profissão.
\end{abstract}

Palavras-chave: Pibid. Formação inicial de professores. Biologia.

Abstract: The creation of public policies to encourage teaching, as is the case of Pibid, has sought to improve initial teacher training and encourage graduates to pursue a teaching career. The objective of this work was to analyze the importance of the Pibid in the initial formation of the graduates of the biology course of the Federal University of Piaui (UFPI), in the Petrônio Portela, Teresina campus. To that end, a questionnaire containing six questions was applied to 36 scholars from Pibid, and the analysis of the results showed that this Program has awakened in these students a greater interest in teaching, in addition, they feel more prepared to act in teaching. It is concluded that the Pibid/Biology subproject of the UFPI has provided scholarship recipients with experiences in the basic education school, encouraging the graduates to become more interested in teaching and making them more prepared for the adversities of the profession.

Keywords: Pibid. Initial teacher training. Biology.

Resumen: La creación de políticas públicas de incentivo a la docencia, como es el caso de Pibid, ha intentado mejorar la formación inicial de profesores y animar a los licenciandos a seguir la carrera docente. Este trabajo tuvo como objetivo, analizar la importancia del Pibid en la formación inicial de los licenciandos del curso de Biología de la Universidad Federal de Piauí (UFPI), campus Ministro Petronio Portela, Teresina. Para ello, se aplicó un cuestionario que contenía seis preguntas, para 36 becarios del Pibid, y el análisis de los resultados mostraron que este Programa ha despertado en esos estudiantes mayor interés por la docencia, además, se sienten más preparados para actuar en la enseñanza. Se concluye que el subproyecto Pibid / Biología de la UFPI ha propiciado a los becarios, experiencias en el ámbito de la escuela de educación básica, despertando en los licenciados, mayor interés por la docencia y haciéndolos más preparados para las adversidades de la profesión.

\footnotetext{
${ }^{1}$ Submetido em: 29 jan. 2019 - Aceito em: 01 jul. 2019 - Publicado em: 19 dez. 2019

${ }^{2}$ Secretaria Estadual de Educação do Piauí (Seduc-PI)/Instituto Nacional de Pesquisas da Amazônia (INPA) E-mail: junielsonbio10@gmail.com

${ }^{3}$ Universidade Federal do Piauí (UFPI) - E-mail: stephanne.marques@hotmail.com

${ }^{4}$ Universidade Federal do Piauí (UFPI) - E-mail: romildochristine@ hotmail.com
} 
Palabras clave: Pibid. Formación inicial de profesores. Biología.

\section{Introdução}

A formação inicial dos professores no Brasil vem sendo discutida nos últimos tempos e se caracteriza por ser um desafio para as Instituições de Ensino Superior (IES) formadoras de docentes, bem como para as políticas educacionais, que devem formar professores capazes de valorizar o aluno como sujeito da construção de seu conhecimento, tornando-o protagonista do seu aprendizado, além de ser capaz de refletir sobre sua ação docente, trabalhar de modo interdisciplinar e integrado ao Projeto Político Pedagógico Escolar, bem como aos documentos oficiais que regem à educação, como a Lei de Diretrizes e Bases da Educação (LDB), Estatuto da Criança e do Adolescente (ECA) e Base Nacional Comum Curricular (BNCC) (MASETTO; GAETA, 2015).

A preocupação com a formação de professores e com suas condições de trabalho não são recentes. Os cursos de licenciatura permanecem sem alterações significativas em seu modelo de formação, havendo necessidade de alterações urgentes, que proporcionem uma formação mais abrangente, possibilitando experiências práticas da realidade escolar (SILVA; SCHNETZLER, 2011; GATTI, 2016). Gatti (2016) ressalta a importância da formação do professor formador, pois eles são intermediadores que compartilham com seus alunos o conhecimento, haja vista que a educação envolve pessoas com diferentes níveis de conhecimento. Sendo assim, é importante discutir e compreender não só a formação, mas também a carreira e as condições de trabalho desse profissional, fato que proporcionará melhorias educacionais.

Diante do atual cenário da formação de professores para atuação na educação básica, diversos estudos têm procurado compreender tal problema. É comum o aluno entrar em um curso de licenciatura sem ter definido sua escolha profissional, levando-o a inquietações por ter que exercer a docência. A formação docente deve estimular e incentivar o aluno a perceber-se professor, situação que pode acontecer em diferentes aspectos. Um deles é o aprender a ser professor pelo modelo de professores, outro é entender sua formação como um processo que está em permanente construção (GALIAZZI, 2003).

Segundo Gatti (2014), há falta de interesse dos estudantes concludentes do ensino médio pela carreira docente, especialmente por áreas como matemática, física, química e biologia. Para comprovar esse fato, basta analisar o número de matriculados nesses cursos e, observa-se que vem diminuindo ano após ano. Outro grande problema é a evasão dos acadêmicos nos cursos citados, que atinge cerca de $70 \%$.

Segundo Marafelli, Rodrigues e Brandão (2017), grande parte dos alunos que escolhem cursar licenciatura não pretende atuar como professor. Isso pode ser explicado pelos baixos salários, desvalorização social desse profissional, por suas condições de trabalho cada vez mais precárias, e pelo aumento das exigências em relação à docência. Embora tenha aumentado as exigências em relação ao professor, a sua formação continua basicamente a mesma de anos atrás, que não prepara-o para enfrentar os conflitos e os desafios das escolas. 
Essa situação demanda ações voltadas aos cursos de licenciatura, em suas condições de oferta, no sentido de valorizá-los, reforçando suas características específicas e resgatando seus valores (APARÍCIO, 2011; GATTI, 2013). Algumas pesquisas mostram que programas voltados para qualificação na formação inicial de professores, como o Programa Institucional de Bolsas de Iniciação à Docência (Pibid), de iniciativa do Ministério da Educação, fomentado pela Coordenação de Aperfeiçoamento de Pessoal de Nível Superior (CAPES), vem contribuindo para um aprimoramento dos cursos de licenciatura nas instituições que os ofertam, além de atrair os estudantes da educação básica das escolas parceiras para cursos de licenciaturas (APARÍCIO, 2011; GATTI, 2013).

Outros estudos têm constatado a contribuição desse Programa na formação inicial de professores, pois o envolvimento com a realidade da escola durante a graduação coopera para que os acadêmicos possam decidir se, de fato, desejam seguir a carreira docente (TORRES et al., 2013; SANTOS; SOARES; SCHEID, 2015; FRISON; VEIGA; CIGALES, 2017).

O Pibid é constituído por bolsistas, os pibidianos, responsáveis por desenvolver atividades ligadas ao ensino nas escolas públicas parceiras; professores supervisores, atuantes na escola pública, onde orientam e supervisionam os licenciandos; coordenadores de área, que são professores do curso de licenciatura na IES, cujo papel é a liderança, o planejamento das atividades teóricas e práticas no âmbito da universidade; coordenadores institucionais e de área de gestão, docentes da instituição de ensino superior, que acompanham a execução do programa na instituição e são responsáveis por repassar as informações para a CAPES. Todos os envolvidos recebem bolsa remunerada para o desenvolvimento das atividades desenvolvidas no âmbito da escola (BRASIL, 2010).

$\mathrm{Na}$ Universidade Federal do Piauí (UFPI), o Pibid foi instituído pela Portaria do Ministério de Educação - MEC no 38, de 2007, e pela Resolução CEPEX nº 223, de 2008, com o objetivo de inserir os licenciandos em formação inicial no ambiente escolar, buscando a valorização docente, despertando o interesse para atuação na educação básica e, consequentemente, melhora na qualidade do ensino nas escolas conveniadas e naquelas onde os futuros profissionais forem atuar por meio das práticas desses profissionais (BRASIL, 2007).

No âmbito da UFPI, o programa estabeleceu parceria com a Secretaria de Educação do Estado do Piauí, e em 2009, iniciou as atividades com acadêmicos das áreas de física, matemática, biologia, química, letras-português e geografia, que passaram a desenvolver atividades em duas escolas estaduais em Teresina-PI. Em 2014, o subprojeto Pibid/UFPI teve uma ampliação, e, desde então, passou a atuar em 49 escolas públicas na capital, com um total de 1.560 acadêmicos bolsistas, de todas as licenciaturas oferecidas pela IES, e 260 professores supervisores.

O curso de licenciatura em biologia da UFPI passou a integrar as ações do Pibid desde o primeiro edital, em 2009. Inicialmente contava com oito pibidianos, um professor supervisor e um professor coordenador de área, atuando em uma escola da capital. Em 2012, passou a atender duas escolas, cada uma com nove bolsistas e uma professora supervisora. A partir de 2014, o subprojeto integrava 60 bolsistas, seis supervisores e três coordenadores de área, desenvolvendo trabalhos em seis escolas estaduais. 
Desse modo, considerando que o Programa da CAPES visa incentivar a docência, especialmente para atuação na educação básica, o presente estudo teve como objetivo analisar a importância do Pibid na formação dos bolsistas do subprojeto biologia da UFPI, Teresina.

\section{Metodologia}

A pesquisa abordou aspectos qualitativos e quantitativos e foi realizada no campus Ministro Petrônio Portela, da Universidade Federal do Piauí, em Teresina. O critério para inclusão dos participantes na pesquisa era de que fossem alunos cursando a partir do terceiro período e de que tivessem, ao menos, quatro meses de vivência como bolsistas no Pibid.

Inicialmente, realizou-se uma triagem dos pibidianos que se enquadravam nos critérios, foi esclarecida a natureza da pesquisa, justificativa, objetivos, métodos, potenciais benefícios e riscos, como preconiza o art. $2^{\circ}$ da Resolução ${ }^{\circ} 510$, de 07 de abril de 2016 (BRASIL, 2016), e solicitado aos que concordaram em participar da pesquisa $(n=35)$ que assinassem o Termo de Consentimento Livre e Esclarecido (TCLE).

Um questionário contendo quatro perguntas de múltipla escolha (fechadas) e duas descritivas (abertas), como mostra o Quadro 1, foi aplicado aos participantes. Eles foram nomeados de pibidianos e atribuído número de 1 a 35 , para garantir o anonimato dos sujeitos da pesquisa. Segundo Gil (1999, p. 128) o questionário pode ser definido "como a técnica de investigação composta por um número mais ou menos elevado de questões apresentadas por escrito às pessoas, tendo por objetivo o conhecimento de opiniões, crenças, sentimentos, interesses, expectativas, situações vivenciadas etc".

Quadro 1. Questionário aplicado aos acadêmicos bolsistas do Pibid/biologia/UFPI.

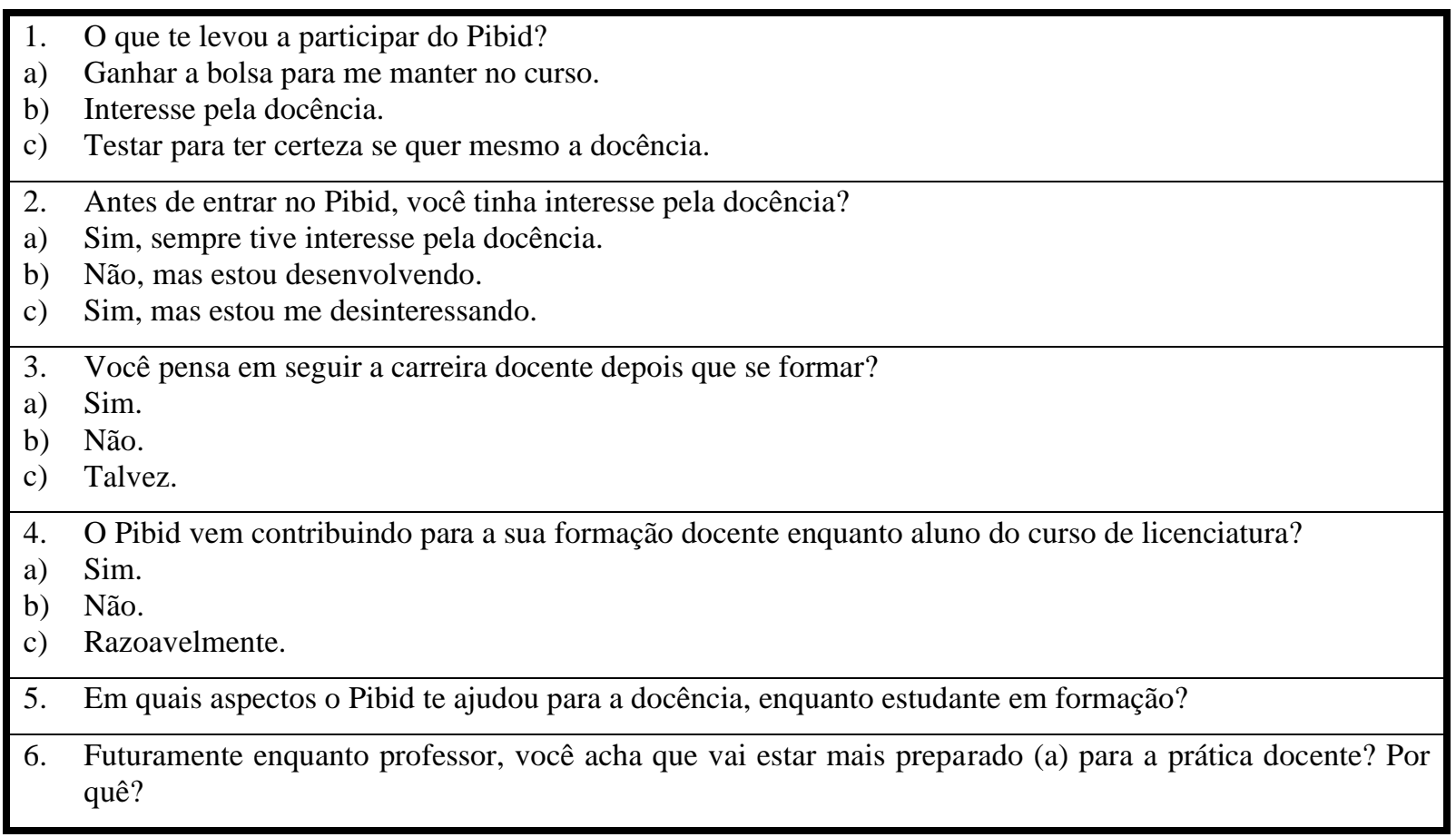

Fonte: Elaborado pelos autores. 
Feito isto, as respostas foram analisadas, baseando-se no método de sistematização de Minayo (2000) e Bardin (1979). Foi utilizado como ferramenta para a tabulação dos dados e montagem de gráficos o software Excel 2010.

\section{Resultados e discussão}

Ao questionar os pibidianos sobre o que os levou a participar do Pibid, 38\% afirmaram que foi por interesse pelo exercício da docência, 32\% declararam que foi para ganhar a bolsa e se manter no curso, e $30 \%$ disseram ter interesse em testar a experiência para ter certeza se quer seguir a carreira docente (Figura 1).

Figura 1. O que te levou a participar do Pibid?

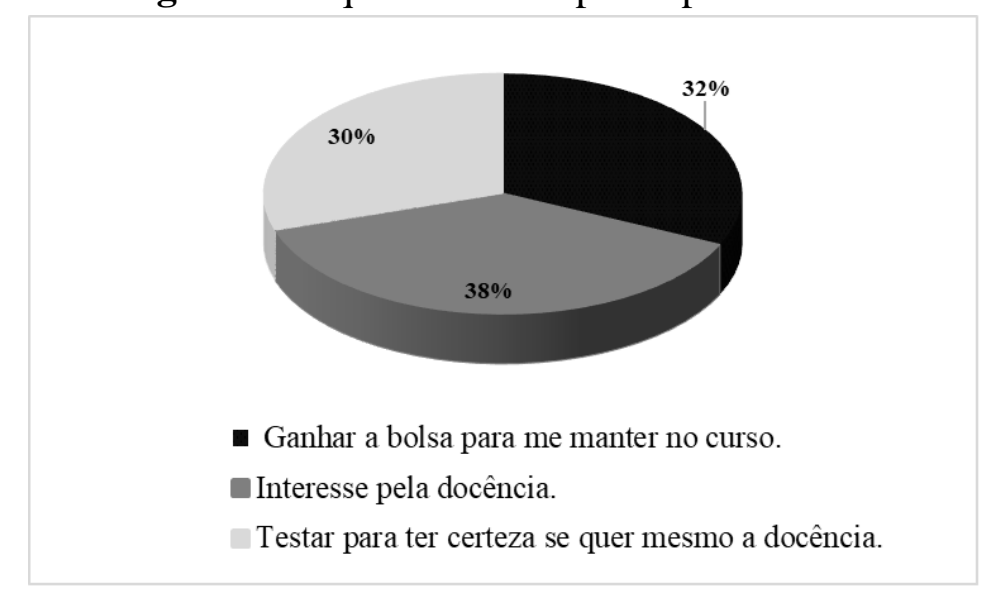

Fonte: Elaborado pelos autores.

Os dados mostram que, embora a maioria dos alunos ingressaram no Pibid por ser um programa de incentivo à docência, alguns participaram não pela possibilidade de experimentar a docência, e sim pela dúvida quanto à escolha do curso de licenciatura, sendo que o Pibid auxiliaria na certeza se desejavam seguir a carreira docente. Outros foram atraídos pela remuneração, que pode ser uma fonte de renda para manter os gastos do curso.

Em estudo semelhante, Ribeiro (2013) identificou que inicialmente os alunos foram atraídos pela bolsa de estudos, mas a inserção na escola proporcionou uma visão diferenciada sobre a finalidade do programa. Do mesmo modo, Ambrosetti et al. (2013) verificou que o valor da bolsa foi um atrativo para os licenciandos entrarem no Pibid, mas destaca como fator essencial, o contato próximo com a escola e com situações cotidianas do professor. Isso mostra que políticas de permanência nos cursos de formação de professores com bolsas remuneradas, são determinantes para atrair alunos e reduzir a evasão nos cursos de licenciaturas, tendo em vista a desvalorização da profissão, que se destaca como um fator desfavorável aos cursos de formação de professores.

Quando questionados se antes de entrar no Pibid já tinham interesse pela carreira docente, $65 \%$ afirmaram que já tinham interesse, $30 \%$ declararam não possuir interesse, mas 
que, aos poucos, esse vem sendo desenvolvido, e 5\% disseram que tinham interesse, mas estão se desinteressando (Figura 2).

Figura 2. Antes mesmo de entrar no Pibid, você tinha interesse pela docência?

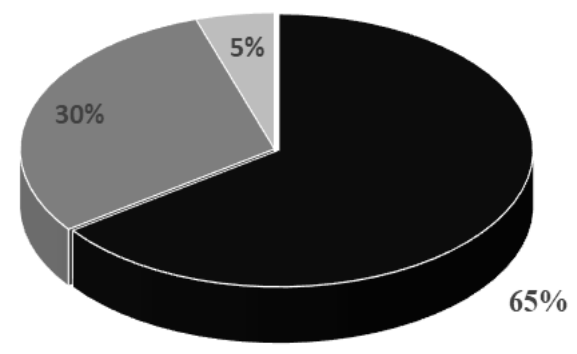

- Sim, sempre tive interesse pela docência.

- Não, mas estou desenvolvendo.

- Sim, mas estou me desinteressando.

Fonte: Elaborado pelos autores.

Diante disso, percebe-se que o programa tem papel importante, pois proporciona experimentação aos bolsistas que são atraídos pela carreira. Do mesmo modo, Moryama, Passos e Arruda (2013), em uma investigação a respeito da aprendizagem docente de pibidianos de um curso de licenciatura em Ciências Biológicas, constataram que os envolvidos na pesquisa demonstraram crescente interesse pela docência. Sendo assim, acredita-se que o programa tem alcançado seu objetivo que é incentivar à docência.

Ao questionar os alunos se pensam em seguir a carreira docente depois de formados, $70 \%$ responderam que sim, $30 \%$ disseram que talvez sigam a carreira e nenhum participante afirmou não querer exercer a docência ao se formar (Figura 3).

Figura 03. Você pensa em seguir a carreira docente depois que se formar?

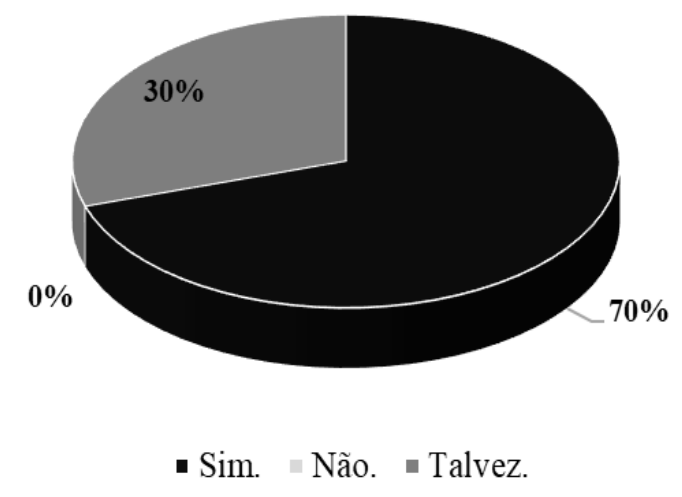

Fonte: Elaborado pelos autores. 
Os dados revelam que o Pibid proporciona aos licenciandos a experiência com a sala de aula, o que os leva a se sentirem mais motivados e atraídos pela docência. Essas informações corroboram os achados de Amorim e Araújo (2017), em um estudo com pibidianos, em que identificaram que a maioria dos participantes da pesquisa manifestava vontade de lecionar em escola pública, a partir das experiências propiciadas pelo Programa. Em contradição aos objetivos do programa, Felício (2014) observou que o Ensino Superior é o nível almejado pelos pibidianos para o exercício da docência quando profissionais, provavelmente devido à melhor remuneração.

Perguntou-se aos entrevistados se o Pibid contribui com a formação docente dos acadêmicos, $87 \%$ acreditam que sim, enquanto $13 \%$ acham que contribui razoavelmente e não houve quem discordasse da contribuição do Programa (Figura 4).

Figura 4. O Pibid vem contribuindo para a sua formação docente enquanto aluno de um curso de licenciatura?

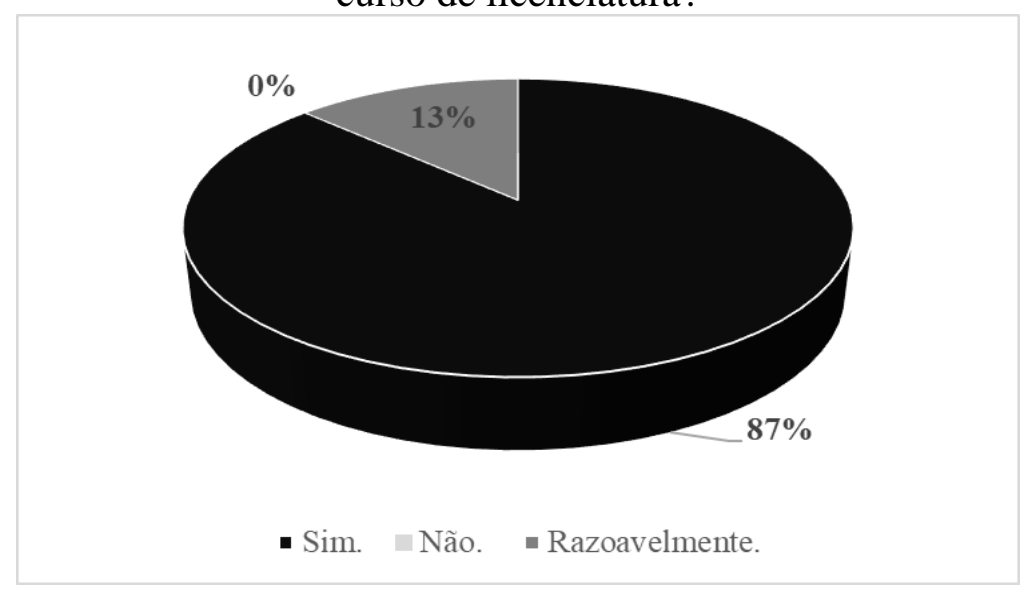

Fonte: Elaborado pelos autores.

Desse modo, acredita-se que os alunos que já demonstram interesse em exercer a docência, quando entram no Pibid para vivenciar experiências proporcionadas pelo programa, no âmbito da sala de aula de uma escola da educação básica, buscam desenvolver uma maior percepção do "ser professor". A parceria promovida pelo Pibid, entre universidade e escola da educação básica permite interações ricas em aprendizagens, como entre professor e aluno, pibidianos e professor titular, pibidianos e prática pedagógica (FRISON; VEIGA; CIGALES, 2017), bem como o compartilhamento de experiência entre professores da educação básica e licenciandos em formação, sendo apontada por Santos, Soares e Scheid (2015), como um fator motivacional dos alunos bolsistas do Pibid.

Procurou-se saber a contribuição do Pibid na formação dos licenciandos, por meio da pergunta: Em quais aspectos o Pibid te ajudou para a docência, enquanto estudante em formação? Por meio das respostas, verificou-se que os licenciandos consideram positivo o Pibid, pois o contato com a sala de aula proporciona viver experiências, como pode-se observar nas falas:

Adquirir experiência, contato com os alunos, desenvolver atividades em sala de aula, ser pontual, responsável e imparcial (Pibidiano 06). 
Me colocou em contato com a escola, com os alunos e por meio disso tenho obtido experiências na área docente (Pibidiano 14).

O programa me mostrou uma nova possibilidade de ensino, com uma metodologia menos tradicional, na qual, se utiliza a criatividade para o desenvolvimento do saber. E isso está sendo fundamental para complementar minha formação acadêmica (Pibidiano 23).

Diante disso, verificou-se que a proximidade com a escola, propiciando a execução da prática docente é bastante valorizado pelos licenciandos, pois eles acreditam que essa vivência irá torná-los mais experientes. Os futuros professores ressaltam que o Pibid tem contribuído para se tornarem mais responsáveis e esforçados, qualidades importantes para um bom docente, comprometido com seu papel social de formar recursos humanos.

Além da melhora nas atitudes em sala de aula, o controle emocional (redução da insegurança, facilidade de comunicação), principalmente em momentos de apresentação, tanto na escola, quanto na universidade, foram apontados como contribuições do Pibid:

Ser responsável, esforçado, conseguir experiência e desenvolver atividades práticas com os alunos, além de me ajudar a enfrentar a insegurança quando estou em sala de aula (Pibidiano 19).

O Pibid me ajudou em relação à comunicação na hora dos trabalhos e na postura diante da sala de aula (Pibidiano 28).

Essas características são fundamentais em um professor para lidar com as mais diversas situações em sala de aula. Gonçalves e Magnabosco (2006, p. 622), consideram "importante ao professor aprender a controlar as suas emoções para não se tornar a maior vítima das situações imprevisíveis que ocorrem em sala de aula".

Também foi apontado que o Pibid contribui oportunizando o emprego de metodologias alternativas que complementam as aulas teóricas, como é o caso dos jogos educativos desenvolvidos pelos bolsistas do Pibid/biologia da UFPI e de outras IES, bastante utilizados em sala de aula e com grande aceitação, bem como a sensibilidade em diagnosticar os problemas enfrentados na carreira docente para que sejam sanados.

Contribui de certo modo pelo fato de sempre aliar as aulas teóricas expositivas a outras metodologias de ensino, e avaliando-as quanto a sua contribuição para o ensino aprendizagem (Pibidiano 31).

No sentido de vivenciar o ambiente escolar (sala de aula), percebendo como agir e perceber os possíveis problemas encontrados durante a docência. Além de me mostrar ferramentas que auxiliam no ensino-aprendizagem dos alunos (Pibidiano $35)$.

Nessa perspectiva, Freitas (2002) afirma que o contato do licenciando com a escola proporciona-o aprender valores, crenças e formas de concepção do mundo. Para o sociólogo Soczek (2011), ao permitir o contato dos futuros professores com a escola, onde mergulham nas atividades escolares, o Pibid amplia e torna mais crítica a concepção de docência, propiciando uma melhoria da formação acadêmica. 
As atividades práticas, desenvolvidas no âmbito do Pibid, permitem aos licenciandos construírem propostas metodológicas e elaborarem modelos didáticos para usarem nas aulas de biologia. Desse modo, "os participantes do Pibid têm produzido uma enorme quantidade de materiais didáticos como jogos, livros, blogs, vídeos, dentre outros, e incentivado o uso mais intenso da estrutura escolar disponível aos laboratórios e bibliotecas" (SOCZEK, 2011, p. 65).

De acordo com Brito, Mello e Araújo (2012, p. 10), o Pibid motiva à luta pela melhoria da qualidade do ensino básico e pela valorização do magistério, os licenciandos acreditam que ele contribui para ação docente, proporcionando "a melhoria na postura em sala de aula, principalmente nos discursos; o aperfeiçoamento das técnicas de ensino; a melhoria da escrita acadêmica; a melhoria do currículo; e o aprofundamento de conhecimentos específicos". Martins, Leite e Cavalcante (2018), destacam que a prática pedagógica de ex-bolsistas do Pibid de biologia, da Universidade Federal do Ceará, revelou que as aprendizagens construídas no decorrer do Programa foram essenciais para conhecer melhor a profissão e a escola pública, para pensar sobre os desafios de ser professor, especialmente na relação professor-aluno, na seleção e elaboração de metodologias de ensino inovadoras, bem como no pensar e refletir sobre sua própria prática.

$\mathrm{Na}$ pergunta "Futuramente enquanto professor, você acha que vai estar mais preparado(a) para a prática docente? Por quê?" Verificou-se que os entrevistados acreditam que estarão melhor preparados para serem professores em função do Pibid, como observado nas falas a seguir:

\footnotetext{
Sim, pois dentro da graduação estou adquirindo conhecimento, atribuindo e obtendo ferramentas que irão e estão por influenciar na carreira docente, juntamente com o Pibid (Pibidiano 7).
}

Sim, pois com o Pibid a gente está convivendo com alunos em sala de aula, que será o lugar onde todo dia vamos trabalhar. Por isso é muito importante para nós enquanto estudantes (Pibidiano 12).

Sim, pois o Pibid possibilita ao aluno a prática à docência, além do mais o convívio com os alunos, possibilita o conhecimento da realidade escolar (Pibidiano 20).

Os futuros professores consideram a interação com os alunos em sala de aula importante, pois veem como uma forma de preparo para a prática docente, e o Pibid além de inserir o licenciando no âmbito escolar, proporciona convívio com a sala de aula. No subprojeto Pibid/biologia, atividades desenvolvidas pelos pibidianos, como monitoria para sanar dúvidas dos alunos, aplicação de jogos educativos, apresentação de palestras sobre temas transversais, constituintes dos Parâmetros Curriculares Nacionais (PCN's), participação nas aulas de biologia com supervisão do professor titular, dentre outras, proporcionam melhor preparo para sua atuação, que começa com o estágio supervisionado, em que os licenciandos do curso de biologia necessitam planejar e executar aulas em turmas dos anos finais do ensino fundamental e ensino médio.

O uso de recursos didáticos diferenciados foi bastante evidenciado pelos bolsistas como ferramenta importante para tornar as suas futuras aulas mais atrativas, garantindo o 
aprendizado. O conhecimento da realidade da escola foi visto como uma possibilidade de reflexão e ação para solucionar as dificuldades da sala de aula, como observa-se nas falas:

Sim, pois no Pibid tive contato com experiência que me ajudará muito, como metodologias inovadoras (Pibidiano 25).

Estarei me sentindo um pouco mais preparado para a docência, porque no programa vivenciamos um pouco o ambiente escolar, com práticas educativas na escola. $\mathrm{E}$ aprendemos práticas que adotaremos em nossa futura profissão de docente (Pibidiano 31).

Acredito que sim, pois uma vez que participo do processo de formação dos alunos (da escola) enquanto pibidiana, conheço um pouco a realidade da sala de aula e as dificuldades do ensino aprendizagem. Isso me possibilita reflexão e ação, uma vez que através das práticas pedagógicas tentamos solucionar tais dificuldades (Pibidiano 35).

Percebe-se que as diversas situações vivenciadas na prática pelos pibidianos os ajuda a desenvolver inteligência emocional e segurança, tornando-os mais preparados para lidar com as adversidades do dia a dia da profissão. É de grande valia que o professor seja inovador em suas aulas para garantir o interesse e proporcionar aprendizado aos seus alunos, e o Pibid tem ajudado nesse sentido. Barbosa e Soares (2012) salientam que o Pibid tem contribuído para que todos os envolvidos no projeto, percebam a escola como um espaço de formação e construção de conhecimentos, além de fomentar diversas práticas pedagógicas, como metodologias de ensino.

Nesta perspectiva, Soczek (2011, p. 62) considera que:

A inovação do Pibid reside na possibilidade de, além das disciplinas de estágio, fornecer um tempo de reflexão e prática pedagógica, contribuindo para a melhoria da práxis profissional mediante reflexões e experiências práticas, numa perspectiva coletiva, de troca de experiências.

Diniz et al. (2010) argumentam que políticas públicas de formação docente são capazes de transformar a educação do país e melhorar o ensino em todos os seus níveis, proporcionando experiências que geram aprendizagens eficazes, pois ao tempo que formam professores capazes de desenvolver recursos e metodologias inovadoras em sala de aula, despertam no aluno da escola maior interesse pelo saber, aprender e pela produção do conhecimento.

Segundo Pimenta (2011), é preciso conhecer e ter instrumentos necessários para a aprendizagem e, nesse sentido, experimentar e praticar são formas de construir conhecimentos. É importante que o futuro professor conheça a realidade escolar, local onde vai atuar futuramente, para saber lidar com as dificuldades da sala de aula e concepções alternativas dos alunos. Sobre isso, Santos, Soares e Scheid (2015, p. 11), destacam que "o licenciando que, durante a sua formação inicial, estiver integrado à realidade das escolas de educação básica, poderá ter uma boa base pedagógica para atuar como profissional da educação".

Diante da necessidade de se formar professores mais reflexivos para a atualidade, Tardif (2007, p. 230) realça que: 
Um professor de profissão não é somente alguém que aplica conhecimentos produzidos por outros, não é somente um agente determinado por mecanismos sociais: é um ator no sentido forte do termo, isto é, um sujeito que assume sua prática a partir dos significados que ele mesmo lhe dá, um sujeito que possui conhecimentos e um saber-fazer provenientes de sua própria atividade e a partir dos quais ele a estrutura e a orienta. A prática pode ser vista como um processo de aprendizagem por meio do qual os professores retraduzem sua formação e a adaptam à profissão, eliminando o que lhes parece inutilmente abstrato ou sem relação com a realidade vivida e conservando o que pode servir-lhes de uma maneira ou de outra.

Para Freire (1987), o processo de transformação social se dá a partir do momento em que o indivíduo se entrega inteiramente a conhecer, sendo necessário o mínimo de base inicial de conhecimento. Portanto, esse é um movimento dialético, pois ao mesmo tempo que o indivíduo conhece porque pratica, ele precisa conhecer para praticar. Desse modo, o Pibid exige do licenciando o mínimo de conhecimento e preparo para poder dar o suporte aos alunos que buscam seu auxílio.

Como salientam Borges et al. (2010, p. 165):

É comum o desinteresse pela profissão docente, a evasão dos cursos de formação dos professores, ou dúvidas após a conclusão do curso; é comum também que os licenciados explicitem atitudes de incerteza e insegurança mediante a prática docente [...]. Tal realidade exige mudanças no processo de formação docente.

Desse modo, a vivência das experiências proporcionadas pelo Pibid, aos futuros professores ainda durante a formação inicial, é de grande importância e poderá reduzir o gargalo do desinteresse pela profissão docente, indo ao encontro da proposta do Ministério da Educação (BRASIL, 2008) ao criar o programa, visando promover a inserção dos estudantes no contexto das escolas públicas desde o início da sua formação acadêmica para que desenvolvam atividades didático-pedagógicas sob orientação de um docente da licenciatura e de um professor da escola.

\section{Considerações finais}

O subprojeto Pibid/biologia da UFPI vem atingindo os objetivos propostos pelo Programa da CAPES, pois tem proporcionado a inserção dos futuros mestres no âmbito escolar, oportunizando vivências com professores experientes, para o desenvolvimento de atividades didático-pedagógicas, incentivando-os ao exercício da docência.

O Pibid/biologia tem possibilitado aos bolsistas, dentre as várias contribuições, vivenciar na prática, a realidade do ensino nas escolas de educação básica, local em que trabalharão futuramente. Fato este que tem cooperado para despertar o interesse nos acadêmicos de licenciatura, inclusive dos estudantes que apresentavam dúvidas no que diz respeito a seguir a carreira docente.

As experiências vividas pelos pibidianos, como a interação com o aluno da escola, o desenvolvimento de metodologias diferenciadas e tradicionais funcionais, torna-os mais 
conscientes de sua escolha profissional e de seu papel social de formador e transformador dos alunos, sujeitos em formação.

Além disso, o Programa possibilita ao bolsista ampliação do seu conhecimento e lhe fornece bases para proporcionar aos seus alunos a construção de saberes. Desse modo, os bolsistas do Pibid/biologia ressaltam que o Projeto tem contribuído para sua formação e se sentem melhor preparados para "ser professor". Sendo assim, o licenciando que durante sua formação passa pelo Pibid, poderá ter suporte teórico-prático e saberá lidar melhor com as adversidades do dia a dia da profissão.

\section{Referências}

AMBROSETTI, Neusa Banhara et al. Contribuições do Pibid para a formação inicial de professores: o olhar dos estudantes. Educação em Perspectiva. Viçosa, v. 4, n. 1, p. 151174, jan./jun. 2013.

AMORIM, Jasmin Guimarães dos Santos; ARAÚJO, Túlio Augusto Velho Barreto de. O Pibid e o lugar da docência na carreira dos licenciandos da UFPE e UPE. In. V Encontro Nacional sobre o Ensino de Sociologia na Educação Básica - ENESEB. Brasília: DF, 23 a 27 de julho de 2017.

APARÍCIO, Ana Sílvia Moço. Formação docente em questão: o que evidenciam os relatos reflexivos produzidos por alunos de pedagogia participantes do Programa Bolsa Alfabetização. Relatório de Pesquisa: Estágio Pós-Doutoral. São Paulo: Fundação Carlos Chagas, 2011.

BARBOSA, Silvia Maria Costa; SOARES, Júlio Ribeiro. A importância do PIBID no contexto da educação brasileira para a formação de professores no Brasil. In: Anais do I Seminário e II Encontro PIBID/Unicamp. Campinas: SP, 14 e 15 de maio de 2012.

BARDIN, Laurence. Análise de conteúdo. Lisboa: Edições 70, 1979.

BORGES, Maria Célia et al. A Formação de professores na UFTM: o Pibid como experiência desafiadora. Revista Triângulo. Uberaba: MG, v. 3. n. 2, p. 163-176, jul./dez. 2010.

BRASIL. Coordenação de Aperfeiçoamento de Pessoal de Nível Superior - CAPES. Pibid Programa Institucional de Bolsa de Iniciação à Docência. 03 set. 2008. Disponível em: http://www.capes.gov.br/educacao-basica/capespibid/pibid. Acesso em: 15 jun. 2017.

BRASIL. Decreto no 7.219, de 24 de junho de 2010. Dispõe sobre o Programa Institucional de Bolsa de Iniciação à Docência - PIBID e dá outras providências. Diário Oficial da União, seção 1, n. 120, p. 4-5, jun. 2010.

BRASIL. Portaria Normativa $\mathbf{n}^{0}$ 38, de 12 de dezembro de 2007. Dispõe sobre o Programa Institucional de Bolsa de Iniciação à Docência - PIBID. Diário Oficial da União, seção 1, n. 239, p. 39, dez. 2007. 
BRASIL. Resolução no 510, de 7 de abril de 2016. Ministério da Saúde. Conselho Nacional de Saúde. Diário Oficial [da] República Federativa do Brasil. Brasília: DF, seção 1, p. 44-46, 24 maio 2016.

BRITO, Luana Patrícia Silva de, MELLO, Rachel Costa de; ARAÚJO, Mônica Lopes Folena. Contribuições do programa institucional de bolsa de iniciação à docência (PIBID) à formação inicial de professores de biologia na universidade. In: Anais do IV Encontro de Pesquisa Educacional em Pernambuco. Caruaru: PE: FUNDAJ, 13 e 14 set. 2012.

DINIZ, Carlos Alberto Malveira et al. Reflexões sobre o processo de ensino aprendizagem da disciplina Geografia, no âmbito escolar. Revista Geográfica de América Central. Costa Rica, n. especial, p. 1-13, 2011.

FELÍCIO, Helena Maria dos Santos. O Pibid como "terceiro espaço" de formação inicial de professores. Revista Diálogo Educacional. Curitiba, v. 14, n. 42, p. 415-434, maio/ago. 2014.

FREIRE, Paulo. Ação cultural para a liberdade e outros escritos. 8. ed. São Paulo: Paz e Terra, 1987.

FREITAS, Maria Nivalda de Carvalho. Organização escolar e socialização profissional de professores iniciantes. Cadernos de Pesquisa. São Paulo, n. 115, p. 155-172, mar. 2002.

FRISON, Lourdes Maria Bragagnolo; SIMÃO, Ana Margarida Veiga; CIGALES, Juliana Ribeiro. Aprendizagens na docência: Pibid e a formação de professores. Revista eCurriculum. São Paulo, v. 15, n. 1, p. 25-44, jan./mar. 2017.

GALIAZZI, Maria do Carmo. Educar pela pesquisa: ambiente de formação de professores de ciências. Ijuí: RS, Ed. Unijuí, 2003.

GATTI, Bernardete Angelina. Avaliação qualitativa dos projetos Pibid implementados em instituições de Ensino Superior - IES localizadas nas regiões Sudeste e Sul. Relatório Técnico. São Paulo: OEI/CAPES, 2013.

GATTI, Bernardete Angelina. Formação Inicial de Professores para a Educação Básica: pesquisas e políticas educacionais. Estudos em Avaliação Educacional. São Paulo, v. 25, n. 57, p. 24-55, jan./abr. 2014.

GATTI, Bernardete Angelina. Formação de professores: condições e problemas atuais.

Revista Internacional de Formação de Professores (RIFP). Itapetininga, v. 1, n. 2, p. 161$171,2016$.

GIL, Antônio Carlos. Métodos e técnicas de pesquisa social. 5. ed. São Paulo: Atlas, 1999.

GONÇALVES, Josiane Peres; MAGNABOSCO, Fatima Luciana. O controle emocional em docentes do ensino fundamental e médio, segundo a perspectiva de professores e alunos. In: Anais do VI EDUCERE - Congresso Nacional de Educação. Curitiba - PR, p. 622-644, 2006. 
MARAFELLI, Cecilia Maria; RODRIGUES, Priscila Andrade Magalhães; BRANDÃO, Zaia. A formação profissional dos professores: um velho problema sob outro ângulo.

Cadernos de pesquisa. São Paulo, v. 47, n. 165, p. 982-997, set. 2017.

MARTINS, Maria Márcia Melo de Castro; LEITE, Raquel Crosara Maia; CAVALCANTE, Maria Marina Dias. Influência do Pibid na formação e na prática de professores de Biologia. Educação em Foco. Juiz de Fora, ano 21, n. 33, p. 75-97, jan./abr. 2018.

MASETTO, Marcos Tarciso; GAETA, Cecilia. Os desafios para a formação dos professores do ensino superior. Revista Triângulo. Uberaba, v. 8, n. 2, p. 04-13, jul./dez. 2015.

MINAYO, Maria Cecilia de Souza. O desafio do conhecimento: pesquisa qualitativa em saúde. 7. ed. São Paulo: Hucitec, 2000.

MORYAMA, Nayara; PASSOS, Marinez Meneghello; ARRUDA, Sergio de Mello. Aprendizagem da docência no PIBID-Biologia. ALEXANDRIA: Revista de Educação em Ciência e Tecnologia. Florianópolis, v. 6, n. 3, p. 191-210, nov. 2013.

PIMENTA, Selma Garrido. O estágio na formação de professores: unidade teoria e prática? 10. ed. São Paulo: Cortez, 2011.

RIBEIRO, Suzicássia Silva. Percepção de licenciandos sobre as contribuições do PIBID Matemática. 2013. 212 f. Dissertação (Mestrado Profissional em Educação). Universidade Federal de Lavras, Lavras, MG, 2013.

SANTOS, Marcia Zschornack Marlow; SOARES, Briseidy Marchesan; SCHEID, Neusa Maria Jonh. O Pibid e a formação de professores de Ciências Biológicas da URI, Santo Ângelo, Brasil. Interacções. Portugal, v. 11, n. 39, p. 155-174, 2015.

SILVA, Rejane Maria Ghisolfi da; SCHNETZLER, Roseli Pacheco. Estágios curriculares supervisionados de ensino: partilhando experiências formativas. EntreVer. Florianópolis, v. 01, n. 1, p. 116-136, 2011.

SOCZEK, Daniel. PIBID como formação de professores: reflexões e considerações preliminares. Formação Docente. Belo Horizonte, v. 3, n. 5, p. 57-69, ago./dez. 2011.

TARDIF, Maurice. Saberes docentes e formação profissional. 8 edição. Petrópolis, RJ: Vozes, 2007.

TORRES, Cícero Magérbio Gomes et al. Formação do professor de biologia: uma análise a partir do programa institucional de Bolsa de Iniciação à Docência (PIBID). Revista

Interfaces: Saúde, Humanas e Tecnologia, v. 1, n. 1, p. 17-33, mar. 2013.

\section{Agradecimentos}

Expressamos nossos agradecimentos ao Programa Institucional de Bolsas de Iniciação à Docência-Pibid e à Universidade Federal do Piauí-UFPI, pelo apoio e incentivo a este trabalho, bem como aos sujeitos da pesquisa. 